\title{
A CONEXÃO E A PREVENÇÃO NOS TRIBUNAIS: O RESPEITO AO DEVIDO PROCESSO LEGAL E AS POSSIBILIDADES DA CONEXÃO IMPRÓPRIA
}

\author{
THE CONNECTION AND PREVENTION IN THE COURTS: RESPECT FOR DUE PROCESS \\ OF LAW AND THE POSSIBILITIES OF IMPROPER CONNECTION
}

\section{Francisco José Rodrigues de Oliveira Neto}

\begin{abstract}
Doutor e Mestre em Direito pela Universidade Federal de Santa Catarina (UFSC); Professor em Direito da Universidade Federal de Santa Catarina (UFSC); Professor do Programa de Pós-graduação Mestrado e Doutorado em Direito da Universidade do Vale do Itajaí-SC (UNIVALI); Desembargador do Tribunal de Justiça do Estado de Santa Catarina. Email: franciscojneto@uol.com.br
\end{abstract}

Recebido em: 06/11/2018

Aprovado em: 03/03/2019

RESUMO: Vigente o novo Código de Processo Civil, vários institutos foram criados para promover a uniformização de entendimento a respeito de temas judicializados que tenham algum nível de semelhança entre si. A busca pela segurança jurídica tornou-se uma das principais características da nova legislação. Nessa esteira, ao lado do tradicional conceito de conexão, outra regra mais aberta foi prevista, além da expressa previsão de que tal igualmente deve ser aplicado aos recursos. Contudo, é preciso recordar que, além de tais normas exigirem cuidado no seu manejo - já que tratam de modificação e fixação de competência e isso pode resultar em violação do princípio do juiz natural - nem sempre será possível alcançar a tão desejada solução idêntica para casos semelhantes em um Tribunal através da conexão. Há situações que dela escapam, de modo que a mera possibilidade de juízos divergentes sobre uma mesma questão jurídica deve ser enfrentada pelo chamado sistema de julgamento dos casos repetitivos, e não por uma espécie de "conexão por afinidade".

Palavras-chave: Devido Processo Legal; Juiz Natural; Competência; Conexão; Prevenção nos Tribunais; Recursos.

\begin{abstract}
In force the new Code of Civil Procedure, several institutes were created to promote the standardization of understanding regarding judicialized issues that have some level of similarity between them. The search for legal certainty has become one of the main features of the new legislation. In this treadmill, alongside the traditional concept of connection, another more open rule was envisaged, in addition to the express provision that this should equally be applied to resources. However, it should be remembered that, in addition to these rules, they require careful handling - since they deal with modification and establishment of competence and this may result
\end{abstract}


in violation of the principle of the natural judge - it will not always be possible to achieve the same desired solution for cases similar in a court through the connection. There are situations that escape it, so that the mere possibility of divergent judgments on the same legal issue must be faced by the so-called repetitive case judgment system, not by a kind of "affinity connection."

Key-words: Due Process; Natural Judge; Jurisdiction; Connection; Prevention in the Courts; Appeals.

SUMÁRIO: Introdução; 1 A Constituição de 1988 e o Princípio do Juiz Natural; 2 As Regras de Competência da Legislação Processual Civil. 3 A Conexão e a Prevenção nos Tribunais; Considerações Finais; Referências.

\section{INTRODUÇÃO}

Com a vigência da nova legislação processual civil, se há uma característica que se pode apontar como fundamental no novo conjunto normativo é a busca da segurança jurídica. Princípio que decorre do devido processo legal, a resposta única a questões semelhantes em tempos de excessiva judicialização da vida cotidiana, se tornou quase uma obsessão.

Inúmeros são os dispositivos e institutos processuais criados para colocar a segurança jurídica como um dos elementos fundamentais dos pronunciamentos judiciais. O chamado feito pelo art. 926 do Novo Código de Processo Civil, que dispõe que "os tribunais devem uniformizar sua jurisprudência e mantê-la estável, íntegra e coerente" (BRASIL, 2015), e a criação do Incidente de resolução de demandas repetitivas, bem demonstram a intenção do legislador em relação a isso.

Nessa esteira, igualmente se modificou o instituto da conexão. Ao lado de sua previsão tradicional - chamada de conexão própria - surge uma outra, a conexão imprópria, atendendo a antigo reclamo da doutrina e da jurisprudência de que, dada a impossibilidade da normatividade capturar toda a realidade fática, necessária uma regra mais aberta para permitir a reunião de processos e, com isso, evitar pronunciamentos divergentes.

Analisar as possibilidades e limitações da modificação de competência pela conexão é o objetivo desse estudo: até que ponto é possível reconhecer a conexão, própria ou imprópria, nos processos em fase recursal, sem que tal importe em violação do princípio do juiz natural (decorrente que é do princípio do devido processo legal)? Subjacente a isso, a intenção de delimitar o uso do instituto, adequando-o aos parâmetros constitucionais.

Para tanto, utilizando-se de um método de abordagem dedutivo, que impõe a análise dos princípios gerais que informam o assunto, inicia-se com a análise do devido processo legal e do princípio do juiz natural que dele decorre e com o status constitucional. Em um segundo momento a análise se dará em torno das regras de competência positivadas em nosso sistema processual, buscando-se delimitar a compreensão em torno da conexão, sempre utilizando-se da revisão bibliográfica do assunto.

Por fim, em um terceiro e derradeiro item, faz-se a análise das possibilidades de aplicação de tais conceitos e dispositivos aos processos existentes nos Tribunais para, ao fim e ao cabo, concluir que nem sempre haverá possibilidade de se ter uma voz única em termos interpretativos, a não ser que tal se enquadre nos mecanismos processuais para tanto existentes. Em uma frase: em nosso sistema processual não há conexão por afinidade. 


\section{A CONSTITUIÇÃO DE 1988 E O PRINCÍPIO DO JUIZ NATURAL}

Editada a Constituição da República de 1988, inaugurou-se entre nós um novo momento político, jurídico e social. Nesse documento, construído após um processo de assembleia nacional constituinte que contou com a participação dos mais diversos setores da sociedade, é possível perceber o modo de compreender, de entender e de identificar o Direito no sistema jurídico nacional.

Para um país que, em regra, é de adeptos do positivismo jurídico, fundamental a afirmação de que nosso ordenamento jurídico se dá a partir do texto constitucional, não se admitindo atos (legislativos ou não) editados fora de seu contexto e dos caminhos ali previstos, quer formalmente, quer substancialmente.

Eis o motivo pelo qual é na Constituição da República que, além da declaração de uma série de direitos (a mais extensa da história constitucional brasileira), entendeu-se por bem incluir não só a aplicabilidade imediata dos direitos e garantias fundamentais (art. $5^{\circ}, \S 1^{\circ 1}$ ), regras das mais importantes para a consolidação de um Estado Democrático de Direito, mas também de um conjunto de normas visando à proteção do próprio texto constitucional, que se traduzem, dentre tantos, principalmente no sistema de controle de constitucionalidade.

A mudança não se dá por acaso. Decorre de um movimento maior relacionado a uma alteração de paradigma ocorrida no ocidente. O Brasil passou a se denominar um "Estado Democrático de Direito", expressão que se apresenta como uma superação do antigo "Estado de Direito" e impõe que todas as ações praticadas em nome do Estado tenham sua legitimidade calcada, não mais unicamente na lei e no Poder Legislativo, mas sim em um grau de juridicidade superior, vale dizer, na Constituição Federal. Afinal, é nela onde estarão depositados os elementos materiais que caracterizarão o novo Estado, protegidos por dois institutos fundamentais nessa nova estrutura jurídica.

De um lado, a supremacia constitucional, que sustenta o entendimento de que a Constituição está no topo do ordenamento jurídico de que emana toda sua força normativa. De outro, a rigidez constitucional, que torna especial o momento da elaboração de uma Constituição e retira da maioria o poder de supressão de direitos e garantias, assegurando, assim, direitos à minoria, o que autoriza a afirmação de que o Estado Constitucional é mais do que Estado de Direito, já que o elemento democrático nele introduzido não foi apenas ali colocado para "travar o poder (to check the power); foi também reclamado pela necessidade de legitimação do mesmo poder (to legitimize state power)" (CANOTILHO, 2003, p.100).

Nesse modelo, encontra-se uma constitucionalização da ordem jurídica, processo que se dá através de uma profunda transformação do ordenamento jurídico, ao término do qual, estará o ordenamento totalmente impregnado pelas normas constitucionais, fator determinado pela existência de uma Constituição "extremamente invasora, entrometida (pervasiva, invadente), capaz de condicionar tanto la legislación como la jurisprudência y el estilo doctrinal, la acción de los actores políticos, así como las relaciones sociales" (GUASTINI, 2005, p. 49).

Como bem diz Luigi Ferrajoli (1995, p.11), coloca-se a palavra Democracia no seu devido lugar e sentido, evitando-se a concepção limitada que leva a entendê-la apenas como vontade da maioria e, assim, ignorar

la que es la máxima adquisicion y al mismo tiempo el fundamento del estado constitucional de derecho: la extensión del principio de legalidad también al poder de la

\footnotetext{
${ }^{1}$ ART. $5^{\circ}, \S 1^{\circ}$ As normas definidoras dos direitos e garantias fundamentais têm aplicação imediata. (BRASIL, 1988).
} 
mayoría y, por conseguinte, la rígida sujeción a la ley de todos los poderes públicos, incluindo el legislativo, y su funcionalización a la tutela de los derechos fundamentales constitucionalmente garantizados.

E é nesse cenário, que ganha importância uma das formas de manifestação desse novo modo de ver e compreender o ordenamento jurídico e o sistema político: o devido processo legal.

Evidencia-se, pois, o fato de que o Estado Democrático de Direito necessita de procedimentos, não só legislativos e eleitorais, mas também e especialmente judiciais, para que se dê sua realização. Há então um resgate da compreensão do devido processo legal, cujo primeiro tratamento ocorreu na Inglaterra em 1215, no art. 39 da Magna Charta, documento que marcou o declínio do poder real e a ascensão da nobreza - e da burguesia - naquele pedaço da Europa. É a afirmação de que nenhum homem livre seria detido ou sujeito à prisão, ou privado de seus bens, senão mediante um julgamento regular pelos seus pares e de harmonia com a lei do país.

Entendido inicialmente como o complexo de atos situados entre o momento inicial de comparecimento no juízo de acusação e a sentença condenatória de prisão, teve sua compreensão alargada com o Direito norte-americano e uma série de dispositivos espalhados pelas declarações de direitos surgidas após a Declaração da Independência em 1776 (Maryland, Pensilvânia, Massachusetts, Virgínia, Carolina do Norte e New Hampshire), culminando com sua incorporação à Constituição da Filadélfia nas emendas (Amendments) números V de 1791 e XIV de 1868. A primeira tratava especificamente da impossibilidade de qualquer pessoa ser privada da vida, da liberdade ou da propriedade sem o devido processo legal e a segunda vinculava os estados da federação a esta regra: "Nenhum estado privará qualquer pessoa da vida, da liberdade ou propriedade sem o devido processo legal".

Atualmente, é cláusula prevista em vários documentos internacionais (Declaração Universal dos Direitos do Homem, Convenção Europeia dos Direitos do Homem), que somente foi inserida expressamente em nosso sistema constitucional na Carta de 1988, mais especificamente no art. $5^{\circ}$, inciso LIV, em que está dito que "ninguém será privado da liberdade ou de seus bens sem o devido processo legal", do qual decorre uma série de princípios.

Dentre eles, e para o objetivo que se pretende alcançar mais à frente, merece destaque o princípio do Juiz Natural, colocado em dois dispositivos da nossa Constituição, ambos no art. $5^{\circ}$ : o primeiro no inciso XXXVII, onde está dito que "não haverá juízo ou tribunal de exceção", e o segundo no inciso LIII: "ninguém será processado nem sentenciado senão pela autoridade competente" (BRASIL, 1988).

Disso decorrem três postulados fundamentais: 1) somente são considerados órgãos jurisdicionais aqueles instituídos pela Constituição; 2) ninguém poderá ser julgado por órgão constituído após a ocorrência do fato e, por fim 3) "entre os juízes pré-constituídos vigora uma ordem taxativa de competências que exclui qualquer alternativa deferida à discricionariedade de quem quer que seja" (DIAS, 1974, p. 322).

A competência, como se vê, nada mais é do que a substancialização do princípio do juiz natural, de modo que,

Considera-se competente o juiz como tal definido pela Constituição ou pela lei mediante a indicação taxativa das causas que ele tem a atribuição de julgar. É indispensável, em outras palavras, que entre o juiz e a causa exista uma relação de adequação legítima (Celso Neves), que só a Constituição e a lei definem e só elas podem alterar. Não é lícito impor a alguém um juiz cuja competência não resulte da Constituição ou da lei em vigor no momento da propositura da demanda (CPC, art. 43) - não sendo permitido sequer aos 
mais elevados órgãos do Poder Judiciário alterar as regras de competência estabelecidas no direito positivo (...). (DINAMARCO, 2016, p.336).

Ou ainda, no dizer da jurisprudência do Superior Tribunal de Justiça, ao julgar um Recurso Especial, da relatoria do Ministro João Otávio de Noronha,

A jurisdição somente pode ser exercida por pessoa legalmente investida no poder de julgar como integrante de algum dos órgãos do Poder Judiciário, observados os limites legais definidos pelas regras de competência. O estabelecimento prévio das regras de competência representa o substrato do princípio do juiz natural (BRASIL, 2016).

Como se vê, é a partir do detalhamento do princípio do juiz natural que se encontra a razão fundamental das regras de competência. É dele que nasce a concepção de juiz natural adotada em nosso texto constitucional, que proíbe - de modo expresso e incisivo - a existência de juízo ou tribunal de exceção e a submissão a autoridade sem competência.

O que igualmente aponta para a necessidade de sua estrita observância e para a gravidade de sua desconsideração. A interpretação equivocada das mesmas ou de qualquer dos institutos a ela relacionados como, por exemplo, a conexão, acarreta, de modo direto, violação do princípio do juiz natural e, em consequência, violação do devido processo legal.

\section{AS REGRAS DE COMPETÊNCIA NA LEGISLAÇÃO PROCESSUAL CIVIL:}

Compreendido o sentido da competência e a necessidade de regras para sua materialização, é justamente nessa linha que segue a legislação processual civil. Diz o artigo 44, do CPC/2015 que,

Obedecidos os limites estabelecidos pela Constituição Federal, a competência é determinada pelas normas previstas neste Código ou em legislação especial, pelas normas de organização judiciária e, ainda, no que couber, pelas constituições dos Estados. (BRASIL, 2015).

Ou seja, em vários níveis legislativos e vários atos normativos poderá ocorrer a previsão de competência a órgão judiciário, desde que obviamente a Constituição e a lei o permitam.

Quanto aos critérios para atribuição de competência, há muito a doutrina já os sistematizou, a saber: 1) critério objetivo (relacionada ao conteúdo do processo), que pode ser em razão da pessoa, em razão da matéria ou em razão do valor da causa; 2) critério funcional (qual o juiz) e, por fim, 3) o critério territorial (qual o local).

São elementos presentes em todas as ações judiciais, destacando-se ainda que - como já dito - a competência decorre diretamente do devido processo legal e seus princípios, e:

Embora o ato de distribuição seja um ato administrativo do tribunal, o equivoco na sua realização pode dar azo à configuração de um vício capaz de violar o direito ao juiz natural - na sua dimensão de juiz absolutamente incompetente. Embora se possa a qualquer tempo, enquanto pendente o processo, remeter os autos ao juízo competente (art. 64, CPC/2015), não se pode excluir a possibilidade de ação rescisória por incompetência absoluta do juízo (art. 966, II, CPC/2015). (MARINONI, MITIDIERO, 2016, p. 214)

Pois bem. Fixado isso, essencial examinar as hipóteses de modificação de competência, em especial, a conexão. 
Uma das formas de conexão está disciplinada no art. 55 do CPC/2015, cujo caput prevê: "reputam-se conexas 2 (duas) ou mais ações quando lhes for comum o pedido ou a causa de pedir". (BRASIL, 2015).

O legislador, tratando das hipóteses de modificação de competência relativa e da possibilidade de reunião de processos, definiu a conexão:

com apoio na tradicional teoria dos três eadem, segundo a qual duas ou mais ações ou demandas são idênticas entre si quando têm as mesmas partes, a mesma causa de pedir e o mesmo pedido. Pelo disposto em seu art. 55, a conexidade entre duas demandas ocorre quando um desses elementos coincide entre elas, ou seja, ou a causa de pedir ou o pedido - mas a experiência da vida dos processos mostra que o formalismo cartesiano dessa teoria engessa o conceito de conexidade e desliga-o de suas finalidades por não ser capaz de resolver satisfatoriamente as dúvidas que na prática sempre aparecem. (DINAMARCO, 2018, p. 310)

$\mathrm{E}$ atento a isso foi que o legislador fez nascer uma segunda forma de conexão, prevista no parágrafo $3^{\circ}$ do art. 55, CPC, cuja redação é a seguinte: "serão reunidos para julgamento conjunto os processos que possam gerar risco de prolação de decisões conflitantes ou contraditórias caso decididos separadamente, mesmo sem conexão entre eles" (BRASIL, 2015).

É o que tem sido chamado de "conexão imprópria", que é assim descrita por Freddie Didier Jr.(2016, p.231):

Há, ainda, a previsão expressa de uma regra aberta de conexão em razão do vínculo entre os objetos litigiosos de dois ou mais processos. Se estiverem pendentes duas ações que possam gerar risco de decisões conflitantes ou contraditórias, devem elas ser reunidas, mesmo que não haja identidade de pedido ou de causa de pedir (art. 55, par. $3^{\circ}, \mathrm{CPC}$ ); ou seja, mesmo que não haja conexão nos termos do caput do art. 55 do CPC.

A existência dessa "regra aberta" - que não encontra semelhança com nenhuma outra regra no Código anterior - era um antigo reclamo da doutrina, especialmente a partir de situações em que, fora dos limites previstos no art. 103 do CPC/73, e repetidos no "caput" do art. 55, CPC/2015, que apenas trocou a palavra "objeto" por "pedido", evidente era o risco de decisões conflitantes. Vale dizer, em determinadas situações, em que o grau de semelhança não ensejava o reconhecimento de conexão (igualdade de pedido ou de causa de pedir), ainda assim ocorria a possibilidade de decisões conflitantes.

A esse respeito, José Carlos Barbosa Moreira (1979, p. 123/124), discorreu em tom crítico afirmando que:

São poucos os escritores que, ao versarem sobre a matéria, observam escrupulosamente os lindes conceptuais traçados no texto legal. A maioria, preste embora homenagem ostensiva à noção de conexão baseada sobre identidade parcial de elementos a que alude o art. 103, termina por dilatar os contornos da figura, reconhecendo a ocorrência de conexidade entre as causas que não tem o mesmo objeto nem o mesmo fundamento.

E mais à frente exemplifica: ação de nulidade de contrato com ação de execução do valor do mesmo; consignação de pagamento e a ação de despejo por falta de pagamento. Para ao final dessa linha de raciocínio afirmar que

Mais sincera e menos desconcertante é a atitude de quem, sem rodeios, averba de insuficiente o conceito dado pelo art. 103, ponderando que a hipótese prevista é apenas 
uma, entre as várias em que ocorre a conexão. Em outras palavras: a definição não abrange todo o definido (MOREIRA, p. 126).

Colocada a questão nesses termos e entendida a razão da existência de um dispositivo que prevê uma regra mais aberta para a conexão, importante destacar que a mesma é, com o perdão da repetição, apenas "mais aberta", mas jamais totalmente aberta. Ou seja, o legislador, ao afirmar que "Serão reunidos para julgamento conjunto os processos que possam gerar risco de prolação de decisões conflitantes ou contraditórias caso decididos separadamente, mesmo sem conexão entre eles" (art. 55, parágrafo $3^{\circ}, \mathrm{NCPC}$ ), não abriu o instituto da conexão a toda e qualquer situação em que não haja conexão.

Apenas e tão somente, mais uma vez objetivando abarcar situações que antes escapavam do regramento legal, optou por abrir a possibilidade de conexão quando há risco de decisões conflitantes ou contraditórias em processos separados "mesmo sem conexão entre eles" nos moldes do caput.

Resumindo, mesmo que não haja conexão pelo pedido ou causa de pedir, ela poderá ocorrer em caso de risco de decisões conflitantes ou contraditórias, se decididas de forma separada.

Nas palavras de LUCON (2016, p. 83), tal modalidade de conexão,

leva em consideração o modo como duas ou mais demandas podem se relacionar. A conexão imprópria pode ser qualificada pela acessoriedade (art. 61), por prejudicialidade (art. 313, V), por reconvenção (art. 343), por homogeneidade (art. 55, par. $3^{\circ}$ ) ou por razões pontuais (ad exemplum, arts. 55, par. $2^{\circ}$ e 60 ).

Diddier Jr (2016, p. 232) segue na mesma linha, acrescentando, ainda, aspecto fundamental, qual seja,

a conexão, nesse caso, decorrerá do vínculo que se estabelece entre as relações jurídicas litigiosas. Haverá conexão se a mesma relação jurídica estiver sendo examinada em ambos os processos, ou se diversas relações jurídicas, mas entre elas houver um vínculo de prejudicialidade ou preliminariedade.

E isso é evidente, já que, entendida a conexão como semelhança, é de se notar que nem toda semelhança é significativa aos olhos da lei processual. Basta ver que a identidade de partes é irrelevante. Não há conexão se o mesmo autor e réu litigam em processos diversos.

A questão somente adquire importância se pedido ou causa de pedir forem idênticos, ou se preenchidos os requisitos do já falado parágrafo $3^{\circ}$, do art. 55, CPC. Lembrando que por causa de pedir há de ser entendida a causa remota (questão de fato que precede ao fundamento de direito) e a causa próxima (fundamento de direito).

E aqui cabe um destaque, ainda a respeito de semelhanças entre demandas o fato de determinada situação possibilitar litisconsórcio facultativo por afinidade (art. 113, inciso III, CPC) não acarreta necessariamente conexão. Para que tal ocorra há que se ter a possibilidade concreta decisões conflitantes na mesma relação jurídica. Nem conexão própria, e nem conexão imprópria, ocorrem por mera afinidade. 


\section{A CONEXÃO E A PREVENÇÃO NOS TRIBUNAIS}

No que toca aos Tribunais, a distribuição dos processos é regulada pelo art. 930, caput, do CPC (BRASIL, 2015), "Far-se-á a distribuição de acordo com o regimento interno do tribunal, observando-se a alternatividade, o sorteio eletrônico e a publicidade". A exceção à regra geral está no parágrafo único desse artigo, que prevê: "o primeiro recurso protocolado no tribunal tornará prevento o relator para eventual recurso subsequente interposto no mesmo processo ou em processo conexo".

Colocadas as hipóteses e requisitos necessários ao reconhecimento da conexão (própria ou imprópria), e dentro do objetivo colocado de início, qual seja, delimitar a exata compreensão do que significa "processo conexo" para os fins de abandono da distribuição típica do princípio do juiz natural, e aplicação da exceção apresentada no parágrafo único do art. 930, do CPC/15, percebe-se que o dispositivo apresenta duas situações que merecem exame em separado: 1) a prevenção do relator gerada pelo recurso subsequente relativo ao mesmo processo e, 2) a prevenção do relator gerada pelo recurso subsequente relativo a processo conexo.

Tal demonstra, obviamente, a possibilidade de reconhecimento da conexão e, daí fazendo incidir a prevenção, em processos que estão submetidos à competência funcional do Tribunal de Justiça. Logicamente que a conexão terá seus efeitos melhor aproveitados se for reconhecida ainda na fase instrutória, porque a prova produzida poderá ser uma só para todos os processos, assim como os demais atos e a própria sentença. Contudo, se não for reconhecida em primeiro grau, mas apenas em segundo, ainda assim há utilidade.

Afinal, um dos principais objetivos desse instituto, além da economia processual, é também evitar decisões contraditórias. Sempre que a isso se chega, o sistema judicial perde em confiança e efetividade.

Ao comentar a regra aberta da conexão prevista no já mencionado parágrafo $3^{\circ}$, do art. 55 , CPC/15, e já esmiuçada no item anterior, Arakem de Assis (2016, p.850) destaca que tal,

estabelece a finalidade precípua da modificação da competência: o julgamento conjunto dos processos conexos para evitar decisões contraditórias ou conflitantes. As demais atividades do processo serão conjuntas na medida do possível, mas não constitui o objetivo fundamental.

Este aspecto, bem capturado na lição acima transcrita, sobressai quando se percebe que a nova legislação, além de ampliar as hipóteses de conexão com essa notória e declarada preocupação, previu expressamente a obrigação de uniformizar a jurisprudência dos Tribunais, mantendo-a estável, íntegra e coerente (art. 926 do CPC/15). E não só isso, adotou o sistema de mecanismos de solução de casos repetitivos (incidente de resolução de demandas repetitivas e recurso especial e extraordinário repetitivos), como os colocados no art. 928 do CPC/15, dispositivo que igualmente não deixa de apontar para outra espécie de conexão.

Nesse contexto, conclui-se que a conexão, em síntese, é apenas mais um dos mecanismos previstos pelo legislador para a manutenção da segurança jurídica - e não o único -, e difere dos demais por ter características específicas e claramente identificadas, como já foi amplamente exposto.

E aqui ganha importância o instituto da prevenção, o qual servirá não para determinar a competência como ocorre com a conexão, mas sim para fixar a competência. São regras que incidem após a identificação de que determinado processo é de competência do Tribunal e que 
justificam o abandono da distribuição aleatória, ocorrendo ela de modo direcionado. Ou seja, com o uso da regra da prevenção fixa-se a competência em um órgão julgador do colegiado. Disso decorre, ainda, uma questão fundamental e que exige resposta, qual seja, o recurso é distribuído à câmara ou turma de julgamento, dado que se trata de um órgão colegiado, ou a um juiz específico membro do colegiado?

Em relação a esse ponto, há divergência na doutrina: de um lado Arakem de Assis (2017, p. 245), que sustenta a segunda possibilidade, afirmando que só por decorrência é que tal ocorre em relação ao órgão fracionário, de outro, Marinoni e Miditiero (2016, p.212), afirmando que:

O juiz natural da causa no tribunal é o órgão fracionário. Não é portanto, um dos magistrados que o compõe. Daí que a causa é em primeiro lugar atribuída, de acordo com a competência, ao colegiado; dentro do colegiado é que se procede à atribuição entre seus componentes. Isso quer dizer que não é propriamente o primeiro destinatário da distribuição o magistrado; o primeiro endereço da distribuição é o órgão colegiado.

Colocada a questão, a segunda das interpretações parece a mais adequada. Isso porque, além de ser necessário ter presente que a mais evidente característica de um tribunal é a colegialidade, e não a individualidade dos seus componentes, o que importa em dizer que sempre estará o relator vinculado a um colegiado (tribunal pleno, órgão especial, câmara isolada, etc.) a qual deterá uma competência específica e que obviamente determinará a competência dele, a distribuição será feita em primeiro para a colegialidade a que pertence, e depois ao membro. E o fato de que em vários momentos o legislador localizar na figura do relator o elemento de atração da competência (parágrafo único do art. 930; art. 1012, par. 3º inciso I; art. 1024, par. $1^{\circ}$ ), não impressiona, já que tal ocorrerá enquanto preenchido o primeiro pressuposto de sua atuação: ter a competência funcional por participar do referido órgão fracionário.

É bem verdade ser possível o enfrentamento de modo alternativo dessa questão, desde que previsto no Regimento Interno nos Tribunais. É o que decorre na parte inicial do art. 930, "caput", CPC/2015, e poderia se consubstanciar em, por exemplo, prorrogação de competência funcional para esgotamento de acervo ou para julgamento de embargos de declaração.

Tal poder decorre diretamente do art. 96, inciso I, letra "a", da Constituição Federal e, no dizer de Fredie Diddier Jr e Leonardo Carneiro da Cunha (2016, p.34):

Significa que os tribunais, mediante seus regimentos internos, disciplinam o funcionamento de seus órgãos, com a distribuição de competência a cada um deles. Em outras palavras, a competência funcional e material dos órgãos internos dos tribunais deve ser definida em seus regimentos internos. A competência material e funcional do tribunal é estabelecida pela legislação (em sentido amplo); o regimento interno distribui essa competência do tribunal internamente.

Mas retornando ao ponto inicial e, fixadas as duas premissas acima colocadas - a saber, a importância da fixação da competência em processos nos Tribunais e a compreensão de que a distribuição ocorre para o colegiado e, apenas depois, para o relator - é o momento de enfrentar a questão da conexão e da prevenção, que são tratadas no parágrafo único do art. 930, CPC/2015, onde está dito, repito: “O primeiro recurso protocolado no tribunal tornará prevento o relator para eventual recurso subseqüente interposto no mesmo processo ou em processo conexo." (BRASIL, 2015).

Trata-se de dispositivo que, a uma primeira vista, não oferece grandes dificuldades, já que expõe com clareza as duas situações que pretende disciplinar.

São elas: 
1) Quando, em um mesmo processo, houver mais de um recurso, o protocolo do primeiro, independentemente de seu julgamento já ter ocorrido ou não, resultará em prevenção ao relator daquele para os subsequentes.

É o caso do conhecimento do agravo de instrumento relacionado a antecipação de tutela e a apelação posterior; o julgamento do recurso de apelação e o agravo de instrumento no caso de cumprimento daquela sentença; e outras tantas situações que são fixadas pelo próprio Código (exemplo: art. 1012, par. $3^{\circ}$, inciso I, CPC) e pela legislação esparsa.

Também será o caso das ações que funcionem, em sua essência, como mecanismos recursais. Por exemplo, o mandado de segurança, hipótese que sempre motivou e justificou a adoção de regras de prevenção.

Nesse sentido, e tratando a questão de forma a abarcar todas essas situações, veja-se o que diz o art. 71 do Regimento Interno do Superior Tribunal de Justiça: "A distribuição da ação, do recurso ou do incidente torna preventa a competência do relator para todos os feitos posteriores referentes ao mesmo processo ou a processo conexo, inclusive na fase de cumprimento de decisão [...]". (BRASIL, 2018)

Aqui é importante lembrar as palavras de Pontes de Miranda (1995, p.295) que, ao estabelecer diferenças entre prevenção e conexão, aponta que esta última, em todas as suas espécies, opera "por si só, num só tempo. Se há lapso entre as causas propostas em juízos competentes, ainda que se invoque, durante a primeira, a conexão, a figura é da prevenção".

É justamente por isso que a Súmula 235, do Tribunal da Cidadania, estabeleceu que "A conexão não determina a reunião dos processos, se um deles já foi julgado", texto que foi incorporado no par. $1^{\circ}$, do art. 55, CPC/2015. Observe-se que a referência é à conexão, e não a prevenção, já que essa,

não é propriamente um critério de determinação da competência, e sim de fixação da competência. Devemos supor dois ou mais juízos que, pelas regras gerais, seriam, em tese, igualmente competentes. Pela prevenção, apenas em um deles a competência é fixada, tornando-se os demais incompetentes. (CARNEIRO, 2012, p.141)

Assim, o que se vê é que o legislador ordinário deixou efetivamente a cada Tribunal a possibilidade de - conforme suas peculiaridades e competências - fixar as regras de prevenção, e o regimento interno é local apropriado para tanto. Como dito acima, é dele, Tribunal, a competência para a especificação de competência de cada um dos seus órgãos e membros.

Vale dizer, tal como ocorre nas hipóteses de competência funcional, que se organizar de modo a que cada um dos seus juízes somente poderá trocar de câmara após esgotamento de todo seu acervo ou de que a prevenção de que trata o art. 930, parágrafo único do CPC/2015, seguirá existindo sempre que houver troca de câmara, da mesma forma, será viável; ou ainda, de que um grupo especial terá competência para análise dos pedidos de antecipação recursal e outro para o julgamento do mérito, as regras de prevenção obrigatoriamente deverão seguir o que esta fixado na Constituição Federal e na legislação específica.

Para, além disso, é questão de organização interna de seus trabalhos e ao colegiado é que compete a melhor forma de dispor, sem perder de vista uma questão fundamental, a prevenção "temática" não é prevenção, é competência em razão da matéria. Prevenção, repito, não determina competência, mas sim fixa a competência.

2) O primeiro recurso protocolado no tribunal tornará prevento o relator para eventual recurso subsequente interposto no mesmo processo ou em processo conexo. 
Como já dito em momento anterior, mas que se faz necessário repetir, o objetivo da conexão é, através da reunião de processos, promover o julgamento simultâneo com o objetivo de se evitar decisões contraditórias ou inexequíveis. No Código de Processo Civil essa é uma preocupação constante, o que se dá também pela chamada uniformização da jurisprudência e pelo dever de mantê-la estável, integra e coerente (art. 926, CPC). O mesmo se diga com a inclusão dos julgamentos de casos repetitivos por decisão, em incidente de resolução de demandas repetitivas e recurso especial e extraordinário repetitivos (art. 928, NCPC).

É bem verdade que tal busca enfrenta limitações, as quais são naturais e próprias do sistema. Ainda que sob a égide do Código de Processo Civil de 1973, o Superior Tribunal de Justiça, em Recurso Especial relatado pelo Ministro Teoria Zavascki, bem destacou essa situação:

A mera possibilidade de juízos divergentes sobre uma mesma questão jurídica não configura, por si só, conexão entre as demandas que que suscitada. Tal possibilidade, embora indesejável, é evento previsível, cujos efeitos o sistema procura minimizar com os instrumentos da uniformização de jurisprudência (CPC, art. 476), dos embargos de divergência (CPC, art. 546) e da afetação do julgamento a órgão colegiado uniformizador $\left(\mathrm{CPC}\right.$, art. 555 , par. $\left.1^{\circ}\right)$, dando ensejo, inclusive, à edição de súmulas (CPC, art. 479) e à fixação de precedentes destinado a dar tratamento jurídico uniforme aos casos semelhantes. (BRASIL, 2006).

Colocadas as coisas nesses termos, e feitas as precisões conceituais, o que se vê é que, da mesma forma como ocorre com a prevenção, a conexão igualmente encontra limitações constitucionais e legais para o seu reconhecimento. Não será a partir da mera constatação de que dois resultados diferentes são possíveis que seu reconhecimento poderá ocorrer.

Há necessidade de, respeitando o devido processo legal e o princípio do juiz natural, que os seguintes requisitos sejam observador: 1) Que os processos, sejam de competência originária, sejam de competência recursal, ainda não tenham sido julgados; 2) Que haja uma identidade de causa de pedir ou de pedido (conexão própria), tudo nos termos do art. 55, "caput", CPC/2015 e, 3) que, no caso do parágrafo $3^{\circ}$, do art. $55, \mathrm{CPC} / 2015$ (conexão imprópria), haja uma relação de prejudicialidade ou de subsidiariedade a justificar o reconhecimento da conexão.

\section{CONSIDERAÇÕES FINAIS}

Como apontado no início deste artigo, se há algo marcante em todo o ordenamento jurídico nos últimos anos, tal é a segurança jurídica. A busca de uma resposta única do sistema judicial como um todo, tornou-se - especialmente após a massificação de demandas - uma das preocupações mais constantes do legislador, o que se refletiu não só na reforma constitucional de 2004 (a chamada "Reforma do Poder Judiciário"), mas também em todos os processos legislativos posteriores, culminando no novo modelo processual civil.

As invocações legislativas à construção de uma jurisprudência uniforme, estável, íntegra e coerente; a vinculação máxima ao posicionamento dos Tribunais Superiores e, ainda, a criação de mecanismos aptos a julgamento de demandas repetitivas corroboram de modo claro essa afirmação.

E nessa linha é que se abriu o conceito de conexão. Se antes entendida como uma relação de semelhança marcada pela identidade de causa de pedir e de pedido, agora vem marcada pela possibilidade de, ainda que tal não ocorra, se possa reconhecer a existência de um vínculo de semelhante que determine o enfrentamento da questão de modo único, evitando-se um mal que 
sempre ronda aqueles que se querem soberanos em seus pronunciamentos: a diversidade de decisões. Como ato de império que é a jurisdição obviamente necessita dar respostas únicas.

Contudo, e apesar da legitimidade da pretensão, na implementação dessa justa reivindicação, não se pode deixar de observar todo o conjunto normativo aplicável a espécie, com destaque para os princípios que decorrem do devido processo legal. É dele que nasce a concepção de juiz natural adotada em nosso texto constitucional, que proíbe - de modo expresso e incisivo a existência de juízo ou tribunal de exceção e a submissão a autoridade sem competência.

Para o respeito a ele, há necessidade, como já dito, de que somente aqueles órgãos indicados pela Constituição da República é que poderão ser considerados jurisdicionais. Além disso, tais órgãos somente poderão ser instituídos antes do fato e, por fim, somente juízes pré-constituídos é que poderão conhecer da matéria e emitir pronunciamentos judiciais.

A isso servem as regras de competência - de modificação dela - e, apesar da legitimidade da pretensão, não se pode subverter o ordenamento jurídico e a normatividade a ponto de forçá-los a, como se busca submeter alguém a confessar mediante o uso da tortura, dele extrair hipótese não contemplada.

É o que ocorre com a compreensão de que a conexão imprópria, especialmente nos Tribunais, pode se dar a partir de uma semelhança unicamente determinada pela afinidade de matérias. Para isso não é a conexão ou a prevenção que se aplicam, mas apenas e tão somente os chamados mecanismos de solução de casos repetitivos.

Conexão e prevenção, a isso não servem.

\section{REFERÊNCIAS}

ASSIS, Arakem. Processo Civil Brasileiro. 2. ed. São Paulo: Editora Revista dos Tribunais, 2016. v. I.

ASSIS, Arakem. Manual de Recursos, $8^{\mathrm{a}}$ ed., rev., atualizada e ampliada, Revista dos Tribunais, São Paulo: 2017.

BRASIL. Constituição da República Federativa do Brasil. Brasília, DF: Congresso Nacional, 1988.

BRASIL. LEI No 13.105, DE 16 DE MARÇO DE 2015. Código de Processo Civil. Diário Oficial da União, Brasília-DF, 17 de março de 2015.

BRASIL. SUPERIOR TRIBUNAL DE JUSTIÇA. REsp 1502819/SP, Rel. Ministro JOÃO

OTÁVIO DE NORONHA, publicado no DJe 19/08/2016.

BRASIL. SUPERIOR TRIBUNAL DE JUSTIÇA. R Esp. 594.748-RS, rel. Teoria Albino Zavascki, julgado em 17.08.2006, publicado em 31.08.2016, 1ª turma, STJ..

BRASIL. Superior Tribunal de Justiça. Regimento Interno do Superior Tribunal de Justiça / organizado pelo Gabinete do Ministro Diretor da Revista - Brasília : STJ. 370 p.

CARNEIRO, Athos Gusmão . Jurisdição e Competência. 18 Ed., Saraiva, São Paulo: 2012. 
CANOTILHO J. J. Gomes. Direito Constitucional e Teoria da Constituição. $7^{\mathrm{a}}$ ed.

DIAS, Jorge de Figueiredo, Direito Processual Penal. vol. 1. Coimbra, Coimbra Ed.: 1974.

DIDIER JR, Freddier. Curso de Direito Processual Civil. 18. Ed., vol. 1, Salvador: JusPodivm, 2016.

DIDIER JR, Freddier.Curso de Processo Civil, $18^{\text {a }}$ Ed. Revista, ampliada e atualizada. Salvador: Juspodivm, 2016,.

DIDDIER Jr, Fredie; CUNHA, Leonardo Carneiro da Cunha. Curso de Direito Processual Civil / Meios de impugnação às decisões judiciais e processo nos Tribunais., $13^{\mathrm{a}}$ Ed., reescrita de acordo com o NCPC, 2016, Ed. Juspodivm, Salvador, 2016, vol. 3

DINAMARCO, Cândido Rangel. Instituições de Direito Processual Civil - vol. I, São Paulo: Malheiros, 2016.

DINAMARCO, Cândido Rangel. Comentários ao CPC arts. $1^{\circ}$ ao 69; das normas processuais $e$ da função jurisdicional. São Paulo: Saraiva Educação, 2018.

FERRAJOLI, 1995, Derecho y razón. Madrid: Trotta, 1995.

GUASTINI Ricardo. La constitucionalización del ordenamiento jurídico: el caso italiano. In: Neoconstitucionalismo(s). CARBONELL Miguel (edición). 2ª ed. Madrid: Ed. Trotta, 2005.

LUCON, Paulo Henrique dos Santos. Relação entre demandas. Gazeta jurídica: Brasília, 2016.

MARINONI, Luiz Guilherme, MITIDIERO, Daniel. Comentários ao Código de Processo Civil: artigos 926 ao 975, in Coleção Comentários ao Código de Processo Civil, coordenação Luiz Guilherme Marinoni, Sérgio Cruz Arenhart, Daniel Mitidier São Paulo: Editora Revista dos Tribunais, 2016.

MIRANDA, Pontes de. Comentários ao CPC, tomo II, 3ª ., Ed., $2^{\mathrm{a}}$ tiragem, revista e aumentada, atualização legislativa de Sérgio Bermudes, Rio de Janeiro: Forense, 1995.

MOREIRA, José Carlos Barbosa. “A conexão de causas como pressuposto da reconvenção”, São Paulo, Saraiva, 1979. 